\title{
The difficult patient
}

\section{The role of 'scientific psychiatry' in understanding patients with chronic schizophrenia or severe personality disorder}

\section{R. D. HINSHELWOOD}

Difficult patients create reactions in the staff who care for and treat them. Those professional reactions, in turn, cause more difficulties for the patients and ultimately for the service we run. My thesis in this paper is that people with severe personality disorder provoke two general categories of characteristic responses in their attendants that are specifically associated with a scientific attitude in psychiatry. With difficult patients, staff typically retreat emotionally from their patient, and from their experience. They retreat into what $I$ am calling a scientific attitude. That reaction is then given objective, 'scientific' justification, but in this guise the justifications very specifically blind us to some aspects of what is happening subjectively in the patients and indeed in staff. With these specific patients, that blind-spot crucially feeds back directly into the patients' difficulties. I am not suggesting that those behaviours are unprofessional or unethical; rather the reverse. They have the blessing of being visibly 'scientific'. However, it is important to trace out those professional attitudes, their causes and their consequences.

\section{ATTITUDES AS OBSERVABLE PHENOMENA}

Experimental neuroscience has advanced steadily over two centuries. Psychiatry, like medicine in general, has espoused what might be called the 'scientific attitude'. Scientific is a term with an increasingly precise definition concerning standardised methods of objective observation that produce general categories based on the repeated occurrence of collections of observable phenomena.

At times, this positivist attitude in psychiatry has met with an opposite reaction, a reaction that emphasises the patient as a suffering subject, rather than as an object for scientific description and intervention. Much of the everyday effort of psychiatric teams is devoted to trying to combine both - the observation of the patient as a scientific object and as a human subject. Unfortunately, the separate approaches can become adversarial. This paper will not enter that dispute directly; but more subjective observation can, in fact, prompt productive reflection - reflection not only on the patient's experiences, but also on the way the scientific attitude impacts on the psychodynamics of psychiatric care itself.

This focus recognises that subjective observation cannot occur without reflection on the experience of the observers, in this case the subjective, psychodynamic states of the team. All psychiatric workers have personal reactions to and feeling for the patients in their charge. Since Heimann's (1950) classic paper on countertransference, it is now widely accepted that analysts, and mental health professionals in general, have inevitable emotional reactions to their patients. Sometimes these are difficult reactions to have; that is to say, the member of staff may have difficulty in coping with his or her immediate experience.

Psychoanalytic work has shown that the specific reactions (even disadvantageous ones) frequently reveal precise psychodynamic conditions that can inform us about the specific case. With certain kinds of psychiatric patients the attitudes and reactions of professionals can also serve to inform us about those conditions.

The 'difficult patient' is a label that does not connote a configuration of clinical signs and symptoms; it is not a DSM category. It is a way of describing the state of the professional during the encounter. The term 'difficult' is an evaluation; the professional does not like the patient or something about the patient. He suffers a disagreeable, or 'difficult', feeling.

"I did not like those patients. . . They make me angry and I find myself irritated to experience them so distant from myself and from all that is human. This is an astonishing intolerance which brands me a poor psychiatrist" (Freud, quated in Haynal, 1988, p. 59).

The confession was about patients with psychosis. They were difficult for Freud because he could not relate to and understand them - and he wanted to.

These are subjective experiences and denote attitudes and feelings, which can be studied informatively from a psychodynamic point of view.

\section{A PATIENT WITH PARANOID SCHIZOPHRENIA}

When Freud did attempt to understand a patient who suffered from schizophrenia, it was one he had never met. He 'analysed' the memoirs of a German high court judge, Judge Schreber, who experienced a psychiatric breakdown leading to a chronic psychotic state (Freud, 1911). By reading the memoirs, Freud found perhaps a more comfortable distance from the patient.

The kernel of Freud's analysis was that a crucial event had occurred in the patient's mind. Judge Schreber had suffered an experience in which the whole of his real world had suddenly and completely lost all meaning to him. In the memoir, Schreber referred to this as the 'worldcatastrophe'. Freud then regarded the psychotic symptoms as an attempt at selfcure - that is, to put back some sort of meaning to his world; Schreber termed it 'miracling-up'. Hallucinations and delusions are fabricated on an entirely personal and idiosyncratic basis that ignores the world the rest of us live in. In other words, the problem for someone with schizophrenia seemed to be a loss of meaning itself, together with a synthetic attempt to replace meaning in a manner which is idiosyncratic and appears, to everyone else, to be 'mad'.

A man for whom meaning itself has gone leads, I suggest, to the quality Freud described as 'so distant from myself and from all that is human'. To be a human person is to deal in meanings. Schreber became, in a sense, a non-human object. Barratt (1996) has described careful observation in the psychiatric setting, in which the patient proceeds through a typical course on admission to a psychiatric ward. At first, he is perceived as an object, then to be dismantled as a set of symptoms and pathologies, followed by being reconstructed into a 'worked-up' case, and 
finally reinvested with the subjectivity of a person again. So many who have schizophrenia seem to fail at the last of these steps.

We now know Schreber was the son of a medical man intensely interested in the correct upbringing of children (Schatzman, 1973). This entailed the imposition of a military posture and rigidity upon the child from the earliest age. Head braces, for instance, and sleeping straps or exercises promoting ideal posture were recommended in the father's book (Schreber, 1858). This system became quite widespread in Germany, and Schreber Senior practised it upon his unfortunate son.

So, the Schreber family conceived childrearing as a very mechanical process of correct growth. The relationship between the child and the carer is one of mechanical rather than human contact, of postures rather than meaning. It calls to mind those experiments that Harlow conducted on monkeys reared with figures made of wire to look like adult monkeys (Harlow, 1961). The baby monkey could even suck milk from these mechanical contraptions. This resulted in later confusion about bonding to other live monkeys.

In the relationship between the patient with schizophrenia and the scientific professional, I am mindful of the kind of apparatus - for a magnetic resonance image scan or some other physical and mechanical investigation - into which the head of a patient is inserted. Again there is the reduction of the patient to the status of a mechanical object. Obviously, it is for good investigative reasons, but equally obviously, in the relational context, it epitomises the depersonalising risk for a patient who is vulnerable to losing personal meaning.

This potential for depersonalising the person into a scientific object of study was inflicted upon the childhood of Schreber. It resembles in character the risks a person with schizophrenia runs in clinical psychiatry. This situation is invited by both sides: the patient's removal from the world of ordinary human rapport on one hand, and, on the other, the professional helper's nonplussed retreat into a scientific mode of understanding.

In this category, human significance (or meaning) vanishes for both parties and mental health professionals frequently change into neutral, as it were. We find our humanitarian interest stymied. Similarly, the reaction of families with a member with psychosis is to encourage the removal of that member from the human context into a 'treatment' setting. The mode of being of the family member with schizophrenia changes abruptly in that moment. The person becomes a noisome object, and the family requires the professional to confirm that change (Laing \& Esterson, 1964; Bott, 1976).

\section{SEVERE PERSONALITY DISORDER}

Moving to another category, we have a different situation. Instead of the distanced apathy or incomprehensible 'meanings' typical of relations to patients with schizophrenia, people with severe personality disorder offer the opposite, a relationship too intensely suffused with human feelings - usually very unpleasant ones. These patients operate predominantly within a world of feelings. Characteristically, patients with 'personality disorder' or 'severe personality disorder' (SPD) directly and deliberately (although unconsciously) interfere with our feelings. We feel intruded upon and manipulated - and indeed, we are. We feel

"impelled to conform to a pattern imposed by the patient, so that we begin to feel provoked, hostile, persecuted and [have] to behave exactly as the patients need us to, becoming rejecting and hostile" (Pines, 1978, p. 115).

The experience is disagreeable, and is a kind of abuse of us, of our time and our help. The medical role fails here, and the mental health professional, despite his training, is in danger of being overwhelmed:

- The trademark of SPD patients is an impairment of their interpersonal and social functioning. This makes it difficult to engage many of them in treatment since the clinical encounter with them is frequently marked by negative feelings, both in them but also in the staff involved in treatment. intense and controlling feelings in the latter serve to perpetuate or aggravate an aggressive, or passive-aggressive, response from patients" (Norton et al, 1996, p. 723).

The reaction of the professional to these people is very different from his or her reaction to the patient with schizophrenia. The mental health professional may indeed suffer his own painful mental disturbance: abrupt resignations, illness, anxiety, sudden and unexpected anger, inability to continue working with a patient, massive guilt feelings, despair, envy of patients' acting out, helplessness and exhaustion when faced with patients' devaluation have all been described (Greben, 1983; Drum \& Lavigne, 1987; Miller, 1989).

With SPD, the patient is not depersonalised into an object, but instead strongly retains moral qualities, expressed in a series of condemnatory labels - 'bad' rather than 'mad'. And this often confirms the life experience of such patients whose carers have proved rejecting or worse. A very large number of these patients have a personal history of childhood abuse. Unfortunately, the experience they create for themselves as a result of provoking professional staff in this way justifies again their long-standing suspicion that their carers will turn swiftly into abusers.

In this case, the psychiatrist has lost the role of objective observer, and finds himself an 'abuser'. Confronted in this emotional way, he feels abused by his patient. Increasingly, he fails to see the patient as a patient - one seeking help.

\section{PROFESSIONAL IDENTITY}

These two kinds of patient cause two quite different kinds of difficulty for the professional. However, neither difficulty is a scientific one - a difficulty of diagnosis, treatment or disposal. The difficult patient creates a worker in difficulties, in a personal sense. Then, the professional resorts to different kinds of behaviour, which risk rebounding in deleterious effects on the patients, creating a pair of unfortunate vicious circles.

Persons with schizophrenia invariably invite a depersonalisation as Freud described, and the professional obliges. The patient loses his status as a moral being altogether. The mental health professional can no longer see his patient as a person.

With SPD, he can no longer see the person as his patient. The patient creates a situation of mutual abuse, and the psychiatrist moves from diagnosis to moral evaluation. Diagnostic categories such as 'psychopath' or 'hysteric' usually mean 'the patient is not ill at all and is wasting my time'.

Both these kinds of patient are 'difficult' because the professional is confounded by a patient who does not complement the professional's helping role. There are two assumptions about what a professional does; both are challenged by these patients. The assumptions are:

(a) The professional needs people to inhabit the same 'world of meaning' 
as him; or at least needs the patient's willingness to learn the meanings he can offer them.

(b) The professional helps people unable to help themselves.

The two groups of patients I have described each deny one of these assumptions. With schizophrenia, the patient cannot construct a world of meaning to which others can relate. Rather, his malady is continually to assault coherent meaning. In contrast, the SPD patient re-interprets help as the threat of abuse or exploitation, and leads to both helper and helped feeling violated. The former's identity is undermined, and issues of personal confidence begin to trouble him. What is the reaction? It is, I claim, to stress our scientific identity more. This has two advantages. First, it is a reputable identity, available in our technological society, and it links us more closely with the achievements of scientific medicine. Second, it has the advantage of supporting an emotional neutrality, a distance from an object of study which is difficult and troubles us personally.

Confronted with people who do not accept their assumptions, the professional is in difficulties. In a sense, he does not have a patient and he cannot properly be a professional. On the one hand, with schizophrenia, the patient does not share meanings with the professional; on the other hand the patient with personality disorder does not acknowledge him as a helper.

To study the objective biochemical and neuroscientific processes of schizophrenia is in no way mistaken, but an emphasis in that direction risks being taken advantage of by a person with schizophrenia, who seems dedicated to destroy all that is human. That 'scientific attitude' also runs the risk that an SPD patient over-suspicious of inhuman intent, will believe his fears confirmed.

The interpersonal processes I have described may enhance moves towards scientific objectivity. The specific destructive 'acts' of a patient with schizophrenia challenge the professional to make sense of them. That pursuit of objective knowledge endorses a particular kind of professional identity - as the scientific investigator which can form a buttress against the patient's negative influence on the professional's confidence. This dynamic situation, combined with the fact that modern medicine has also a profoundly scientific orientation, gives a double support to scientific psychiatry. So often, in terms of the steps that Barratt (1996) described, the objective activity of the mental health professional jeopardises, specifically, the fourth step the step in which the patient is reinvested with subjectivity as a person again.

Reactions to experiencing patients with SPD lead to equally deleterious effects. Feeling intrusively exploited, the professional desperately seeks an advantage - by condemning, rejecting and physically discharging of the patient. By spotting the unworthy, the professional again endorses a particular professional identity - as champion of 'scientific psychiatry' against its wanton 'misuse'.

In these two cases, patients' damaging attitudes are unwittingly endorsed by the attitudes of professionals.

These methods of buttressing professional identity also risk causing us to lose sight of rich information about the complex of exploitative relationship problems that is right there in front of us. In both cases, the professional becomes in a sense the difficulty, to the mutual detriment of professional and patient. Moreover, this takes place behind the more glamorous image of the scientific nature of psychiatry.

\section{SCIENTIFIC PSYCHIATRY}

In contemporary psychiatry, we increasingly regard patients with schizophrenia as treatable. On the other hand, SPD patients stand out increasingly as untreatable and unacceptable. What causes the difference?

If schizophrenia is now treatable, with varying degrees of success, it is the reverse of the state of affairs 100 years ago. Then, the standard view was that psychosis should be lumped together with tertiary syphilis and other physical conditions as irretrievable degeneration. With the diagnostic innovations of Kraepelin and Bleuler, and with the advances in psychopharmacology and other neurosciences, it appears obvious that schizophrenia seems more treatable. However, there is no simple relationship between scientific advance and effective treatment. Objective science certainly advances the understanding and treatment of schizophrenia in one way, but it has also changed our emotional responses to schizophrenia, and indeed our attitudes to psychiatry itself.

Owing to our better view of the science, we can support our objectivity when we are with persons ready to be depersonalised. It makes scientific sense to regard the schizophrenic patient as an object, but the problem is that in doing good science we risk cementing the patient even more into his idiosyncratic world. This is a dilemma: by doing good science, we might turn the patient into an object, which can depersonalise someone who has the utmost difficulty in being a person.

Contrast this with the SPD patient. Like it or not, we are drawn into a fierce and involving relationship that gets less and less objective. The feelings in our relationships with them are the problem, because it shakes our view of ourselves as neutral, objective scientists to find ourselves marked down as abusers. From the point of view of objective science, this feels less and less like doing treatment.

Thus, the success of scientific psychiatry allows the patient with schizophrenia to comply in his own depersonalisation, and the SPD patient to re-experience abuse in the place of help.

\section{CONCLUSION}

I have concentrated on two kinds of difficult patient to show that they are difficult because they put us in some personal difficulties. It is not simply that treatment is difficult. Rather, these specific patients challenge assumptions about our identity as scientists, and they become caught in specific traps as a result. Mental health professionals are driven to behaviour of two kinds - although both kinds, on the surface, have scientific respectability. Those interactions, while working to the detriment of patients with both schizophrenia and SPD, psychologically support professionals when their identity is under threat.

In general, our attitudes interleave with those of our patients. Mostly, they combine to ensure cooperative work between the patient and his psychiatric team; but not always. I have cited occasions where the attitudes of patient and staff interact in downward spirals, to the detriment of patients and discomfort of staff. I submit that a study of attitudes, and of the processes in which they are embedded, is necessary and can be helpful when confronted with these incomprehensibly difficult patients.

Owing to the intensity of personal reactions, psychiatry is one of the most difficult branches of medicine to practise. For the same reason, the 'scientific attitude' has to be most strongly struggled for. However, 
while there is a growth in objective understanding for our patients and their psychological conditions, it is important not to neglect the other quite different mode of understanding, the one that comes through a subjective process of inquiring into our own relating to our patients. And the scientific rigour of such subjective inquiry should be as great as in the objective research work.

These comments may seem to polarise the trends in psychiatry between objective and subjective knowledge. However, many psychiatrists and other professionals make great efforts to understand their patients' experience, as well as to investigate their 'neuroscience'. That effort to understand comes not only from psychoanalytic inspiration, since cognitive and behavioural approaches also address very directly the patients' accounts of their life and experiences.

We, as practitioners in psychiatry, are cleft by the philosophical issues of the mind-brain problem, and we are unlikely to solve what the philosophers cannot. What we must be aware of is how that schism can open up under certain pressures - I have pointed to emotional pressures in the work - and leave us in opposing camps. If psychiatry comes apart at the seams like this it will leave two particular kinds of patient high and dry, and

R. D. HINSHELWOOD, FRCPsych, Professor of Psychoanalysis, Centre for Psychoanalytic Studies, University of Essex. Colchester CO4 3SQ

(First received 8 July 1998, final revision 17 November 1998, accepted 17 November 1998)

pose intractable difficulties that are illunderstood. Instead, our reactions to these groups of patients can inform us that the patient with schizophrenia is shrinking down to a depersonalised object, and that the SPD patient is cultivating his experience of abuse. Such knowledge is not just informative, but is also a strong support in tolerating the difficult feelings that beset us as professionals, and it can enhance our human contact while we continue to do science.

\section{REFERENCES}

Barratt, R. (1996) The Psychiotric Team and the Sociol Definition of Schizophrenio. Cambridge: Cambridge University Press.

Bote, E. (1976) Hospital and society. British journol of Medical Psychology, 49, 97-140.

Drum, P. \& Lavigne, G. (1987) Extended state hospital treatment for borderline patients. Hospital and Community Psychiotry, 38, 515-519.

Froud, S. (19II) Psycho-analytic notes on an autobiographical account of a case of paranoia. Reprinted (1953-1974) in The Standard Edition of the
Complete Psychological Works of Sigmund Freud (trans. and ed. J. Strachey), Vol. 12. London: Hogarth Press.

Greben, S. (1983) The mutti-dimensional inpatient treatment of severe character disorders. Conodion journal of Psychiatry, 28, 97-101.

Harlow, H. F. (1961) The development of affectional patterns in infant monkeys. In Determinants of infont Behoviour (ed. B. M. Foss). Vol. I. London: Methuen.

Haynal, A. (1988) The Technique at issue. London: Karnac.

Heimann, P. (1950) On counter-transference. Internotional journal of Psychoonalysis, 31, 81-84.

Laing, R. D. E Esterson, A. (1944) Sanity, Madness and the Family. London: Tavistock.

Miller, L. J. (1989) Inpatient management of borderline personality disonder: a review and update. fournol of Personality Disorders, 3, 122-134.

Norton, K. Hinshelwood, R. D. (1996) Severe personality disorder. Treatment issues and selection for in-patient psychotherapy. British journal of Psychiatry. 168. 723-73I.

Pines, M. (1978) Group-analytic psychotherapy of the borderline patient. Group Anolysis, 11, 115-126.

Schreber, D. G. M. (1858) Kollipoedie oder Erziehung zur Schönheit durch noturgetreve und gleichmössige förderung normoler Körperbiłdung. Leipzig: F. Fleischer.

Schatrman, M. (1973) Soul Murder. London: Penguin. 